\title{
Outcome and Complications of Phacoemulsification Combined with Pars Plana Vitrectomy
}

\author{
ALI ZAIN UL ABIDIN ${ }^{1}$, MUNIB UR REHMAN², SHAHID MAHMOOD DAYAL ${ }^{3}$ \\ ${ }^{1,2}$ Assistant Professors, ${ }^{3}$ Professor \\ Department of Ophthalmology, Khawaja Muhammad Safdar Medical College, Allama Iqbal Memorial Teaching Hospital, Sialkot \\ Correspondence to: Dr. Ali Zain ul Abidin, E-mail doali4i@gmail.com, Cell 0300-9463804
}

\begin{abstract}
Aim: To determine the outcomes of phacoemulsification also examine the complications associated to phacoemulsification combined with pars plana vitrectomy.

Study design: Observational study

Place and duration of study: Department of Ophthalmology, Khawaja Muhammad Safdar Medical College, Allama lqbal Memorial Teaching Hospital, Sialkot, from $15^{\text {th }}$ July 2020 to $14^{\text {th }}$ January 2021.

Methodology: Twenty patients of both genders whom had undergoing phacovitrectomy were included. Patient's ages were ranging from 20 to 80 years. Patient's detailed medical histories were examined after taking informed consent. Patient's retinal diagnosis, intraocular pressure, visual acuity, intra and post-operative complications were recorded. All the patients had received clear corneal phacoemulsification and 23-guage pars plana vitrectomy.

Results: There were $15(75 \%)$ male patients while 5(25\%) female patients with mean age was $54.52 \pm 12.45$ years. Five patients (25\%) had vitreos hemorrhage, 7(35\%) patients had rhegmatogenous retinal detachment, 3(15\%) patients had intraocular foreign body, 2(10\%) had epiretinal membrane, 2(10\%) had macular hole and $1(5 \%)$ had tractional retinal detachment. Miosis and rupture of posterior capsule were the most common intraoperative complications found in $85 \%$ and $10 \%$. Fibrin was found in $3(15 \%)$ cases, posterior synechia was found in $2(10 \%)$ cases.

Conclusion: The phacoemulsification with pars plana vitrectomy is safe and effective treatment modalities in patients with cataract coexist with vitreoretinal disease.

Keywords: Phacoemulsification, Pars plana vitrectomy, Cataract, Complications, Outcomes
\end{abstract}

\section{INTRODUCTION}

The coexistence of cataract and vitreoretinal conditions is not unique. ${ }^{1}$ This association is somehow difficult to achieve the optimum result - expected not only in the elderly but in cases of trauma, intraocular foreign body, intraocular inflammation and metabolic disorders.

The cataract first of all coincided with its dark grade visualization of the fundus, a worrying surgery. On the opposite, cataract development is considered to cause vitrectomy. In vitreoretinal surgery, lens contact is a possible risk. Finally, the thickened lens restricts the thorough clearing of the glass foundation, which is especially important in cases of proliferational vitreoretinopathy (PVR). In cases with coexisting cataract and vitreoretinopathies up to now, the simultaneous removal of the lens with vitreoretinal surgery seems to be sufficient. The procedure would presumably lead to intraoperative and postoperative complications such as increased fibrin deposition anterior chamber reaction, posterior synechias and increased intraocular pressure (IOP). To date, various studies have measured the effects of combined phacoemulsification and pars plana vitrectomy (PPV). 2-10 The combined method facilitates a quicker recovery and thereby increases cost-effectiveness. ${ }^{11-13}$

The purpose of this study was to investigate the results ofcombined phacoemulsification and PPV (phacovitrectomy)in our patients with coexisting cataract and miscellaneousvitreoretinal disorders.

\section{MATERIALS AND METHODS}

This observational study was conducted at Department of Ophthalmology, Khawaja Muhammad Safdar Medical College, Allama lqbal Memorial Teaching Hospital, Sialkot, from $15^{\text {th }}$ July 2020 to $14^{\text {th }}$ January 2021.A total of 20 patients of both genders whom had undergoing phacovitrectomy were included. Patient's ages were ranging from 20 to 80 years. Patient's detailed medical history was examined after taking informed consent. Patient's retinal diagnosis, intraocular pressure, visual acuity, intra and post operative complications were recorded. The visual acuity of the Snellen was first reported, then converted to a minimum resolution angle logarithm (MAR log) for statistical analysis. The IOP measurements were carried out with the tonometer for Goldmann applanation.

All patients were assessed before surgery and the first month of surgery and when required. Patients under 1 month of follow-up or cases in which the intraocular lens (IOL) could not be inserted were removed for any purpose. There were also no instances of mixed phacoemulsification and silicone oil removal. In terms of IOP, measurements were grouped in four in terms of $<10 \mathrm{mmHg}, 10-19 \mathrm{mmHg}$, $20-29 \mathrm{mmHg}$ and $>30 \mathrm{mmHg}$, for practical purposes. All the patients had received clear corneal phacoemulsification and 23-guage pars plana vitrectomy. All the statistical data was analyzed SPSS-20. 


\section{RESULTS}

Out of 20 patients 15 (75\%) patients were male while $5(25 \%)$ patients were females. Mean age of patients was $54.52 \pm 12.45$ years. There were $11(55 \%)$ right and $9(45 \%)$ left eyes. According to the vitreoretinal diagnosis, 5(25\%) patients had vitreos hemorrhage, $7(35 \%)$ patients had rhegmatogenous retinal detachment, $3(15 \%)$ patients had intraocular foreign body, $2(10 \%)$ had epiretinal membrane, $2(10 \%)$ had macular hole and $1(5 \%)$ had tractional retinal detachment. Miosis and rupture of posterior capsule were the most common intraoperative complications found in $85 \%$ and $10 \%$. Intraoperative rupture was found in (10\%) cases and $1(5 \%)$ case had preoperative ruptured lens capsule. 3(15\%) patients need for iris hook. Endotemponade was used in $85 \%$ cases and in $15 \%$ cases no endotemponade use. Clear corneal sutured in 6 (30\%) cases, Scleral suture in $15(75 \%)$ patients. According to the postoperative anterior segment reaction, $85 \%$ patients had mild, 2(10\%) patients had severe and $1(5 \%)$ had moderate. Fibrin was found in $3(15 \%)$ cases, posterior synechia was found in $2(10 \%)$ cases (Tables 1-3).

Table 1: Demographic details of all the patients

\begin{tabular}{|l|c|l|}
\hline Variable & No. & $\%$ \\
\hline Gender & 15 & 75.0 \\
\hline Male & 5 & 25.0 \\
\hline Female & 3 & 15.0 \\
\hline Age (years) & 15 & 75.0 \\
\hline $20-40$ & 2 & 10.0 \\
\hline $40-60$ & \multicolumn{1}{|l|}{} \\
\hline 6180 & 9 & 45.0 \\
\hline Side & 11 & 55.0 \\
\hline Left & 5 & 25.0 \\
\hline Right & 7 & 35.0 \\
\hline Vitreoretinal Diagnosis & 7 & 15.0 \\
\hline Vitreos hemorrhage & 3 \\
\hline $\begin{array}{l}\text { Rhegmatogenous retinal } \\
\text { detachment }\end{array}$ & 2 & 10.0 \\
\hline Intraocular foreign body & 2 & 10.0 \\
\hline Epiretinal membrane & 1 & 5.0 \\
\hline Macular hole & \multicolumn{1}{|l|}{} \\
\hline Tractional retinal detachment &
\end{tabular}

Table 2: Preoperative, after 1 month and at 12 months finding of IOP

\begin{tabular}{|l|l|l|}
\hline Variable & No. & $\%$ \\
\hline Preoperative (mmHg) & 1 & 5.0 \\
\hline$<10$ & 18 & 90.0 \\
\hline $10-20$ & 1 & 5.0 \\
\hline $21-30$ & - & - \\
\hline$>30$ & \multicolumn{2}{l|}{} \\
\hline At 1 month (mmHg) & 1 & 5.0 \\
\hline$<10$ & 17 & 85.0 \\
\hline $10-20$ & 1 & 5.0 \\
\hline $21-30$ & 1 & 5.0 \\
\hline$>30$ & \multicolumn{2}{|l|}{} \\
\hline At 12 months (mmHg) & - & - \\
\hline$<10$ & 18 & 90.0 \\
\hline $10-20$ & 1 & 5.0 \\
\hline $21-30$ & 1 & 5.0 \\
\hline$>30$ & \multicolumn{2}{|l|}{} \\
\hline
\end{tabular}

Table 3: Intraoperative and postoperative complications

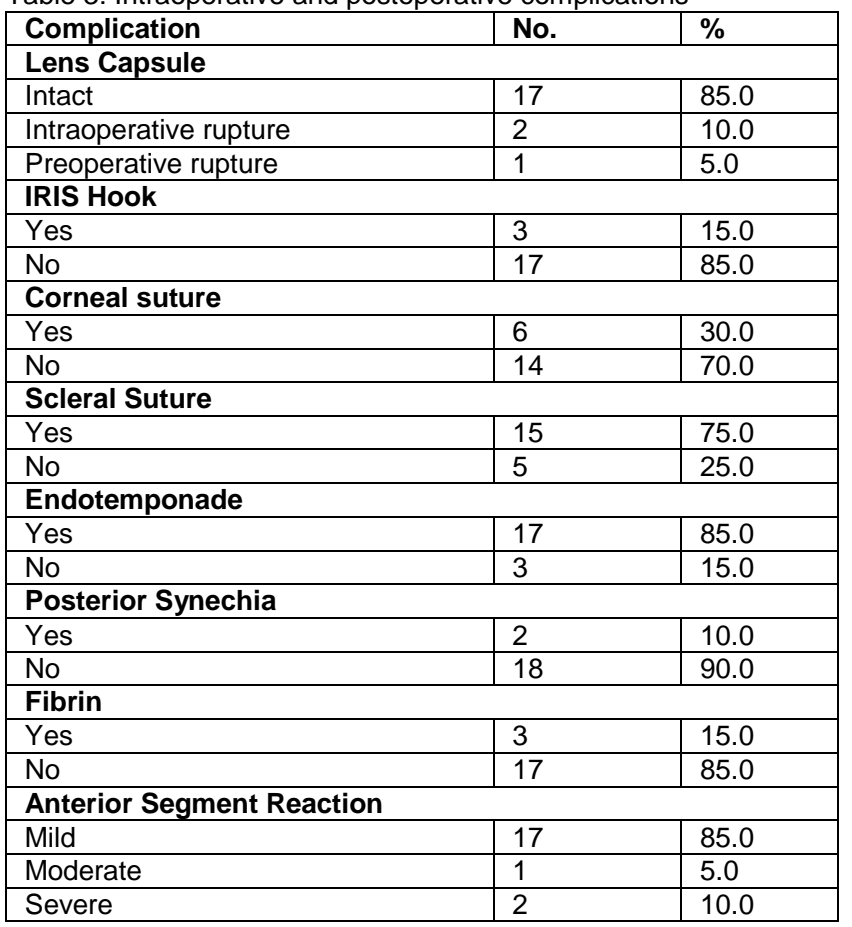

\section{DISCUSSION}

Cataracts with vitreoretinal disorders may lead to surgery. A number of advantages regarding phacovitrectomy have been published. It enables better visualization of the fundus by having direct media. The removal of the vitreous base is especially necessary in RRD cases and PVR cases. The removal of the crystalline lens therefore helps to enhance the visualization and shaving of the vitreous baseline. $14 \mathrm{In}$ addition, a thickened, crystalline lens will end easily with a vitreoretinal instrument intraoperative lens; combo surgery prevents this condition. Finally, the progression of cataracts is a well-known PPV complication. In the 2-year cycle following the PPV, cataract progression was reported to be 80 percent. ${ }^{15,16}$ There were $15(75 \%)$ male patients while 5 $(25 \%)$ female patients with mean age $54.52 \pm 12.45$ years. These results showed similarity to some other studies conducted regarding cataract surgery in which male patients population was high as compared to females 65 to $80 \%{ }^{17,18}$.

In present study, we found $5(25 \%)$ patients had vitreos hemorrhage, $7(35 \%)$ patients had rhegmatogenous retinal detachment, $3(15 \%)$ patients had intraocular foreign body, 2(10\%) had epiretinal membrane, 2(10\%) had macular hole and $1(5 \%)$ had tractional retinal detachment. Most of the patients in our study had rhegmatogenous retinal detachment. A study conducted in turkey regarding combine surgery reported $33.3 \%$ cases had rhegmatogenous retinal detachment ${ }^{19}$. In our study, the most common intraoperative complication was miosis found in $85 \%$ cases. These results showed a bit similarity to other study in which $92.9 \%$ cases had miosis ${ }^{19}$. We found intraoperative rupture in 2 cases. Iris hook need in 3 cases. The risk of posterior capsule rupture is expected to be increased; hence, combo surgery requires enhanced 
surgical experience. Moreover, risk of posterior synechia formation is increased with phacovitrectomy. ${ }^{14}$ In a controlled study, Park et $\mathrm{al}^{20}$ reported that phacovitrectomy cases revealed significantly higher rates of abnormal IOP $(60 \%)$, intraocular fibrin $(30 \%)$, and synechia (30\%) compared to PPV-alone cases. ${ }^{21}$ In present study posterior synechia was found in $2(10 \%)$ cases. A study conducted by $\mathrm{Oh}$ and coworkers ${ }^{4}$ and reported that posterior synechia rate was $6.1 \%$, and the authors concluded that the use of endotamponade and prolonged operation could be the risk factors. Use of iris hooks could potentially be associated with increased inflammation and posterior synechia due to a broken bloodaqueous barrier. However, in this series, we did not find a significant relationship; perhaps, this could be due to relatively small rate of iris hooks use. Intraoperative corneal edema is not an uncommon complication of combined procedures. ${ }^{4}$ The significant corneal edema which would require corneal scraping was not evident in any patient. Perhaps, this is due to the irrigation solution used and the enhanced fluidics of the vitreoretinal surgery machines.

\section{CONCLUSION}

The phacoemulsification with pars plana vitrectomy is safe and effective treatment modalities in patients with cataract coexist with vitreoretinal disease. Moreover, we should have to do more work to reduce the complication rate associated to phacovitrectomy.

\section{REFERENCES}

1. Canan H, Selcuk-Sizmaz S, Altan-Yaycioglu $R$. Surgicalresults of combinedpars plana vitrectomy and phacoemulsificationfor vitreous hemorrhage in PDR. Clin Ophthalmol 2013; 13: 1597-1601.

2. Jain V, Kar D, Natarajan S, Shome D, Mehta H, Jayadev C, et al. Phacoemulsification andpars plana vitrectomy: a combined procedure. Indian J Ophthalmol 2007; 55(3): 2036.

3. Zheng $\mathrm{QX}, \mathrm{Wu} \mathrm{EH}$, Zhang $\mathrm{YP}, \mathrm{Xu} \mathrm{M}, \mathrm{Li}$ WS. Anterior segment complications after phacoemulsification combined vitrectomy and foldable intraocular lens implantation. Int $\mathrm{J}$ Ophthalmol 2010; 3: 249-54.

4. Oh JH, Na J, Kim SW, Oh J, Huh K. Risk factors forposterior synechiae of the iris after 23-gauge phacovitrectomy. Int $\mathrm{J}$ Ophthalmol 2014; 7: 843-9.

5. Tosi GM, Balestrazzi A, Baiocchi S, Tarantello A, Cevenini $G$, Marigliani $D$, et al. Complex retinal detachment in phakic patients: previtrectomy phacoemulsification versus combined phacovitrectomy. Retina 2017; 37(4): 630-36.

6. Koushan K, Mikhail M, Beattie A, et al. Corneal endothelialcell loss after pars plana vitrectomy and combined phacoemulsification-vitrectomy surgeries. Canad $\mathrm{J}$ Ophthalmol 2017; 52(1): 4-8.

7. Silva PS, Diala PA, Hamam RN, et al. Visual outcomesfrom pars plana vitrectomy versus combined pars planavitrectomy, phacoemulsification, and intraocular lens implantation in patients with diabetes. Retina 2014; 34(10): 1960-68.

8. Lee DY, Jeong HS, Sohn HJ, Nam DH. Combined 23-gauge sutureless vitrectomy and clear corneal phacoemulsification in patients with proliferative diabetic retinopathy. Retina 2011; 31(9): 1753-8.

9. Leiderman YI, Andreoli MT, Sun B, Dawood S. Pars plana vitrectomy combined with cataract extraction. Retina 2015; 35(6): 1059-64.

10. Treumer F, Bunse A, Rudolf M, Roider J. Pars plana vitrectomy, phacoemulsification and intraocular lens implantation: comparison of clinical complications in a combined versus two-step surgical approach. Graefe's Arch Clin Experimental Ophthalmol 2006; 244(7): 808-15.

11. Karaca EE, Ozdek S, Ozmen MC, Dursun A, Yalçın NG. Safety of polyacrylamide $1.5 \%$ left in anterior chamber in combined phacoemulsification and pars plana vitrectomy surgery. Curr Eye Res 2016; 41(4): 501-6.

12. Fajgenbaum MAP, Neffendorf JE, Wong RS, Laidlaw DAH, Williamson $\mathrm{TH}$. Intraoperative and postoperative complications in phacovitrectomy for epiretinal membrane and macular hole: a clinical audit of 1000 consecutive eyes. Retina 2018; 38(9): 1865-72.

13. Jabs DA, Nussenblatt RB, Rosenbaum JT. Standardization of the uveitis nomenclature (SUN) working group standardization of the uveitis nomenclature for reporting clinical data: results of the first international workshop. Am J Ophthalmol 2005; 140: 509-16.

14. Pinarci EY, Bayar SA, Sizmaz S, Yesilirmak N, Akkoyun N, Yilmaz G. Anterior segment complications after phacovitrectomy in diabetic and nondiabetic patients. Eur $\mathrm{J}$ Ophthalmol 2012; 23(2): 223-9.

15. Braunstein RE, Airiani S. Cataract surgery results after pars plana vitrectomy. Curr Opinion Ophthalmol 2003; 14(3): 15054.

16. Gui JM, Jia L, Liu L, Liu JD. Vitrectomy, lensectomy and silicone oil tamponade in the management of retinal detachment associated with choroidal detachment. Int $\mathrm{J}$ Ophthalmol 2013; 6: 33-41.

17. Ghosh G, Best K, Steel DHW. Lens-iris diaphragm retropulsion syndrome during phacoemulsification in vitrectomized eyes. J Cataract Refract Surg 2013; 39(12): 1852-8.

18. Lee JY, Kim KH, Shin KH, Han DH, Lee DY, Nam DH. Comparison of intraoperative complications of phacoemulsification between sequential and combined procedures of pars plana vitrectomy and cataract surgery. Retina 2012; 32(10): 2026-33.

19. Hurley C, Barry P. Combined endocapsular phacoemulsification, pars plana vitrectomy, and intraocular lens implantation. J Cataract Refract Surg 1996; 22(4): 4626.

20. Park SP, AhnJK, Lee GH. Morphologic changes in the anterior segment after phacovitrectomy for proliferative diabetic retinopathy. J Cataract Refract Surg 2009; 35(5): 868-73.

21. Benson WE, Brown GC, Tasman W, McNamara JA. Extracapsular cataract extraction, posterior chamber lens insertion, and pars plana vitrectomy in one operation. Ophthalmology 1990; 97(7): 918-21. 